\title{
NEĮGALIŲJŲ, JUDANČIŲ VEŽIMĖLIUOSE, SAVIRAIŠKOS GALIMYBĖS FIZINIO AKTYVUMO PERSPEKTYVOJE
}

\author{
Vilma Stankute் ${ }^{12}$, Laimutė Samsoniené $\dot{e}^{1}$ Algirdas Juozulynas ${ }^{3}$ \\ ${ }^{1}$ Vilniaus universiteto Sveikatos ir sporto centras, ${ }^{2} V i l n i a u s$ universiteto Medicinos fakultetas, \\ ${ }^{3}$ Valstybinis mokslinio tyrimo institutas Inovatyvios medicinos centras
}

Raktažodžiai: neigalieji, savarankiškumas, fizinè veikla, neigalumas

\begin{abstract}
Santrauka
Pripažindami neigaliujų galias fizinèje veikloje, nepriklausomai nuo jų gebejimų, mes sudarome sąlygas jų efektyviam tobulejimui: skatiname jų saviraišką, savivoką, savivertę ir geriname kūno ịvaizdị. Tyrimo tikslas - įvertinti neiggaliujų savarankiškumą bei asmeninę fizinès veiklos patirti ir realų poreiki. Tiriamoji imtis - 29 respondentai su fizine negalia ir judantys neigaliojo vežimèliu. Tyrimas atliktas 2014 m. liepos ir rugpjūčio mènesiais Palangos reabilitacijos ligonineje ir Lietuvos paraplegiku asociacijos lanšafto terapijos ir reakreacijos centre. Tyrimo metodai - siekiant išsiaiškinti asmens igalinimo veiksnius individualiame ir bendrame socialinès aplinkos lygmenyje, per asmens saviraiškos sąlygas, veiklumo ir apsisprendimo galimybes buvo taikytas kokybinis tyrimo metodas, taikant pusiau struktūrizuoto interviu duomenų rinkimo būdą bei atviro ir uždaro tipo orientaciniai klausimai; respondentų savarankiškumo lygi vertinome Barthel ir FIM indeksais. Gauti rezultatai - nepriklausomai nuo negalios sunkumo laipsnio, savarankiškumo lygio ir laiko po traumos ar ligos respondentai fizinię veiklą vertino pozityviai :teigiamos emocijos, nauja patirtis, gera sveikata, teigiamas kūno įvaizdis.
\end{abstract}

\section{İvadas}

Atsisakant tradicinio medicininio modelio ir ji keičiant socialiniu - ugdymo metodu, neigalieji suprantami kaip turintys vienodas teises ir galimybes, kaip ịgalūs asmenys, būti ịgalinti ị visuomenę per fizinị ugdymą, sportą bei rekreaciją. Nepriklausomai nuo igalumo, fizinè veikla yra svarbi keliant asmens savivertę bei formuojant kūno ịvaizdị. Asmuo geba save išreikšti visuomenejje gerais san- tykiais su kitais, turèdamas bendrą teigiamą požiūrị i save ir kitus $[5,6]$. Fizinè veikla - vienas iš pačių tinkamiausių būdų neigaliesiems integruotis visuomeneje: skatinamas poreikis judèti, gaunama ịvairių žinių, skiepijami mokejjimai ir igūdžiai, žadinamos teigiamos emocijos, ugdomos dorovinès nuostatos bei teigiami charakterio bruožai [1-4]. Pozityvaus požiūrio formavimui $i$ asmeninius gebejjimus ir jų ugdymo perspektyvą neigaliujų ịgalinimui svarbus jų savarankiškumo didinimas. Todèl neiggaliųjų kaip ir igaliujų asmenų vidinis apsisprendimas veikti turi būti sąmoningas ir realus [7-10]. Neigaliojo asmens saviraiškos galia remiasi jo savarankiškumo lygiu, kuo didesnè nepriklausomybė nuo aplinkinių, tuo didesnè galimybẻ dabartinius gebejjimus ugdyti ir juos pritaikyti ateities tikslams pasiekti.

Taikomosios fizinès veiklos mokslo krypti veikianti „Asmens saviraiškos teorija“ remiasi Motyvų teorijos idèjomis, kurią pagrindė A. Maslow (1954, 1970). Motyvai yra vidiniai veiksniai -nuostatos, skatinančios veikti; veikiančios priežastis, skatinančias asmens raidą (fizinę, psichologinę ir socialinę); motyvai yra skirtingi ir gali keistis priklausomai nuo asmenybès amžiaus ir aplinkos. Asmens saviraiškos teorijos holistinès ir humanistinès idejjos panaudojamos praktikoje, kada sprendžiamos neigaliujų psichomotorinès problemos siejamos su jų igalinimu ekologinèse sistemose.

Tyrimo tikslas - įvertinti neigaliujų savarankiškumą bei asmeninę fizinès veiklos patirtị ir jos realų poreikị.

\section{Tyrimo objektas ir metodas}

Tyrimas atliktas $2014 \mathrm{~m}$. liepos ir rugpjūčio mėnesiais Palangos reabilitacijos ligonineje (PRL) ir Lietuvos paraplegiku asociacijos lanšafto terapijos ir reakreacijos centre (LPC) (Monciškèse). Tyrime dalyvavo 29 respondentai - 8 moterys (amžiaus nuo 24 iki 52 metu ), 21 vyras (amžiaus nuo 19 iki 65 metai ). Visi asmenys, dèl ịvairaus lygio stuburo pažeidimų, turi judejjimo negalią ir juda neịgaliojo vežimèliu: 
- $\quad$ PRL -17 besigydančių pacientų : 7 moterys (amžiaus nuo 24 iki 52 metų) ir 10 vyrų (amžiaus nuo 19 iki 65 metų); LPC- 12 klientų poilsiaujančių ar dalyvaujančių sporto stovykloje : 1 moteris, 39 metai), 11 vyrų (amžiaus nuo 27 iki 50 metu );

- praejęs laikas po ligos ar traumos (1 lentelè) - nuo 2 mènesių iki 1 metų (m.) - 3 respondentai; nuo $2 \mathrm{~m}$. iki 5 m. -6 respondentai; nuo $6 \mathrm{~m}$. ir daugiau -10 respondentu;

- daugumos respondentų negalia yra igyta ir tik 3 respondentai turi igimtą negalią: vyrai-30 m. ;27 m..; $19 \mathrm{~m}$.

Siekiant išsiaiškinti asmens igalinimo veiksnius individualiame ir bendrame socialinès aplinkos lygmenyje, per asmens saviraiškos sąlygas, veiklumo ir apsisprendimo galimybes buvo naudotas pusiau struktūrizuoto interviu duomenų rinkimo būdas ir atviro bei uždaro tipo orientaciniai

1 lentelè. Tiriamoji imtis

\begin{tabular}{|c|c|c|c|}
\hline & Pažeidimo lygis & Lytis/amžius & $\begin{array}{l}\text { Laikas po ligos/ } \\
\text { traumos/metai }\end{array}$ \\
\hline \multirow{17}{*}{ 롤 } & Centrinė neurofibromatozè (NF2) & Vyras-19 & 2 \\
\hline & C4-5 kompresinis lūžis & Moteris-30 & 7 \\
\hline & GSI & Moteris-24 & 2 \\
\hline & C7 kompresija, mielopatija & Vyras-22 & 1 \\
\hline & C7- Th1 lūžis & Moteris-32 & 2 mėnesiai \\
\hline & $\mathrm{C} 4-5$ & Vyras-24 & 1 \\
\hline & C6-7 kompresinis lūžis & Moteris-48 & 1 \\
\hline & C7 lūžis & Moteris-45 & 8 \\
\hline & Stuburo osteochondrozė & Vyras-52 & 5 \\
\hline & Stuburo kanalo stenozé & Vyras-43 & 3 \\
\hline & C5-6 lūžis & Vyras-30 & 2 \\
\hline & L1-2 disko išvarža & Moteris-49 & 7 \\
\hline & C4-5 & Vyras-38 & 9 \\
\hline & Th12-L1 & Vyras-24 & 2 \\
\hline & Th10-11 & Vyras-39 & 2,5 \\
\hline & C6-7 & Vyras-42 & 5 \\
\hline & GSI & Vyras-65 & 5 \\
\hline & Th 8-9, kojų paralyžius & Vyras-33 & 14 \\
\hline & Kojų parezė & Vyras-30 & 30 \\
\hline & C5-6 hemiparezè & Vyras-42 & 8 \\
\hline & C6 Sunki kojų parezè & Vyras-50 & 7 \\
\hline & C4 - Th 5, kojų ir liemens paralyžius & Vyras-29 & 12 \\
\hline & Mielomeningocelè, kojų paralyžius & Vyras-27 & 27 \\
\hline & $\begin{array}{l}\text { Diskozė, erkinis encefalitas, } \\
\text { raumenų silpnumas }\end{array}$ & Moteris-39 & 16 \\
\hline & Th 6 kojų ir liemens paralyžius & Vyras-39 & 16 \\
\hline & Th 10-11 kojų paralyžius & Vyras-42 & 22 \\
\hline & C 6-7 paraparezè & Vyras-36 & 8 \\
\hline & Th 8-9, kojų paralyžius & Vyras-45 & 15 \\
\hline Uి & $\begin{array}{l}\text { C7 kojų paralyžius, sunki } \\
\text { liemens kontrolè }\end{array}$ & Vyras-32 & 9 \\
\hline
\end{tabular}

klausimai - kokybinis tyrimo metodas.

Respondentų savarankiškumo lygis buvo vertinamas anketine apklausa : Barthel indeksu (asmens savarankiškumas ir aplinkiniu pagalbos poreikis); FIM indeksu (asmenu funkcinio savarankiškumo vertinimas).

Barthel indeksas naudojamas nustatyti aplinkinių pa-

2 lentelẻ. Savarankiškumo vertinimas pagal FIM ir Barthel indeksus

\begin{tabular}{|c|c|c|c|}
\hline & Pažeidimo lygis & FIM & Barthel \\
\hline \multirow{17}{*}{$\vec{a}$} & Centrinè neurofibromatozè (NF2) & 123 & 91,33 \\
\hline & C4-5 kompresinis lūžis & 116 & 74,83 \\
\hline & GSI & 118 & 92,1 \\
\hline & C7 kompresija, mielopatija & 119 & 94,88 \\
\hline & C7- Th1 lūžis & 90 & 54,87 \\
\hline & $\mathrm{C} 4-5$ & 116 & 80,61 \\
\hline & C6-7 kompresinis lūžis & 118 & 87,9 \\
\hline & C7 lūžis & 110 & 78.63 \\
\hline & Stuburo osteochondrozė & 116 & 86,7 \\
\hline & Stuburo kanalo stenozè & 122 & 90,2 \\
\hline & C5-6 lūžis & 118 & 72,7 \\
\hline & L1-2 disko išvarža & 117 & 76,48 \\
\hline & $\mathrm{C} 4-5$ & 86 & 62,3 \\
\hline & Th12-L1 & 122 & 89,6 \\
\hline & Th10-11 & 120 & 80,3 \\
\hline & C6-7 & 109 & 76,8 \\
\hline & GSI & 104 & 72 \\
\hline \multirow{12}{*}{ 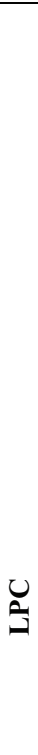 } & Th 8-9, kojų paralyžius & 112 & 72,1 \\
\hline & Kojų parezè & 119 & 81,07 \\
\hline & C5-6 hemiparezė & 116 & 91 \\
\hline & C6 Sunki kojų parezè & 109 & 69 \\
\hline & C4 -Th 5kojų ir liemens paralyžius & 111 & 72,64 \\
\hline & $\begin{array}{l}\text { Operuota mielomeningocelè, kojų } \\
\text { paralyžius }\end{array}$ & 111 & 75,13 \\
\hline & $\begin{array}{l}\text { Diskozè, erkinis encefalitas, raumenų } \\
\text { silpnumas }\end{array}$ & 113 & 76,75 \\
\hline & Th 6 koju ir liemens paralyžius & 103 & 71,42 \\
\hline & Th 10-11 kojų paralyžius & 118 & 70 \\
\hline & C 6-7 paraparezè & 97 & 73,2 \\
\hline & Th 8-9, kojų paralyžius & 118 & 77,12 \\
\hline & $\begin{array}{l}\text { C7 kojų paralyžius, sunki liemens } \\
\text { kontrolè }\end{array}$ & 107 & 80,6 \\
\hline
\end{tabular}


galbos poreikị, panaudojant 10 rodikliu judejjimo ir savęs apsitarnavimo kasdieninio gyvenimo veiksmus ịvertinti: valgymas, persikèlimas, asmens higiena, naudojimasis tualetu, maudymasis, vaikščiojimas/judejjimas véžimèliu, lipimas laiptais, apsirengimas ir nusirengimas, žarnyno funkcijos kontrole; 10 veiksmų vertinama atitinkama balų sistema. Bendras balų skaičius juos sudejjus gali siekti nuo 0 iki 100 : 0-20 balų - visiškai priklausomas; 21-61 balų - beveik visiškai priklausomas; 62-90 balu - vidutiniškai priklausomas; 91-99 balų - šiek tiek priklausomas; 100 balų - nepriklausomas. Funkcinio savarankiškumo įvertinimo (FIM) skale vertinama 18 punktų: valgymas, asmens higiena, maudymasis, viršutinès kūno dalies apsirengimas, apatinès kūno dalies apsirengimas, tualetas, šlapinimosi kontrolè, tuštinimosi kontrolè, persikèlimas: lova, kèdè, vežimèlis, persikèlimas: tualetas, persikèlimas: dušas, èjimas/judejjimas vežimèliu, lipimas laiptais, supratimas, išraiška, socialiniai santykiai, problemų sprendimas, atmintis; punktai ịvertinami nuo 1 iki 7 balų. Kai neigaliajam reikalinga visiška pagalba - 1balas, 2 balai - kai reikalinga maksimali pagalba, t.y. kai neigalusis pats atlieka $25-49 \%$ visų veiksmų, pacientui dažnai reikia pagalbos atliekant pagrindinius veiksmus, 3 balai kai reikalinga vidutiné pagalba, t.y. pats neigalusis atlieka $50-74 \%$ visų veiksmų, 4 balai, kai neigaliajam reikalinga minimali pagalba, t.y. jis atlieka savarankiškai $75 \%$ visų veiksmų, pacientui reikia tik paprastos pagalbos, 5 balai - kai jam reikia tik priežiūros ar paruošimo, 6 - kai neiggalusis yra dalinai savarankiškas, reikia tik papildomų priemonių, 7 balai - kai neigalusis yra pilnai savarankiškas. Bendra balų suma nuo 18 iki 126 balų. (Hamilton ir kt., 1987).

- Duomenų rinkimo procedūra. Interviu metu užduoti klausimai, i kuriuos pacientai atsakè pasakodami apie savo patirti ir galimybes (1 lent.).

\section{Tyrimo rezultatai ir jų aptarimas}

Taikomojoje fizineje veikloje asmens saviraiškos ar priklausomumo teorija pažymi, kad norint pasiekti neįgaliujų savigarbos lygị, pirmiausia turi būti patenkinti jų fiziologiniai, psichologiniai ir fizinio saugumo bei meilès, bendravimo poreikiai. Mūsų respondentų kasdieninė veikla ir gebejjimas ją atlikti savarankiškai buvo vertinami dviem indeksais Barthel ir FIM (2 lentelè).

Tiriant apsitarnavimo funkcijas Barthel indeksu, išskiriami tokie kriterijai: valgymas, persikèlimas, asmens higiena, naudojimasis tualetu, maudymasis, vaikščiojimas/ judejjimas vėžimèliu, lipimas laiptais, apsirengimas ir nusirengimas, žarnyno funkcijos kontrolè. Tuo tarpu funkcinis savarankiškumas(FIM) vertinamas ne tik pagal apsitarnavimą kasdieninejje veikloje, bet ir pagal bendravimo gebè- jimus ir socialinę būklę. Respondentų suvokimas ir išraiška (FIM) vertinama maksimaliu balu, nes asmenys suprato kalbą, raštą, sugebejjo aptarti ir išreikšti kasdienius įvykius bei poreikius, taip pat sugebejo nusakyti bendrus jausmus, požiūrị i š šeiminius ryšius ir santykius. Visų tyrime dalyvavusių neigaliųų socialinis bendravimas, problemų sprendimas ir atmintis buvo ịvertinta didžiausiu galimu balu -7 . Respondentai nepriklausomai nuo savarankiškumo lygio sugeba spręsti kasdienes problemas, sąveikaudami su personalu, kontroliuodami nuotaikas, geba prisiminti kas buvo vakar ar netolimoje praeityje. Ivertinus šiuos aspektus asmenys surenka po 35 balus, kurie padidina bendrą įverčio sumą. Tai galima pastebèti lyginant Barthel ir FIM indeksų vertes, FIM testo ịverčiai 123 - 116 b., o Barthel - 91,33 $-76,48 \mathrm{~b}$.

Tyrimo duomenys parode, kad Barthel indeksas svyruoja nuo 86 b. iki 123 b., dèl pažeidimo lygio ir laiko po traumos ar ligos. Asmuo, kuriam prieš 2 mènesius diagnozuotas C7- Th1 lūžis, pažeidimo lygis nèra aukštas, gali valdyti viršutinę kūno dalị, savarankiškai valgyti, pilnai pasirūpinti asmens higiena, tačiau asmens tualeto, maudymosi bei judejimo veiklose yra visiškai arba dalinai priklausomas. Bendras Barthel ịvertinimas - 54,87 b., o atlikus FIM gaunama 90 b., nes ịvertinus bendravimą bei socialinę buklę - pilnai savarankiškas.

Respondentas 9 metus turintis pažeidimą C 4-5 (po traumos); liemens ir kojų paralyžius, FIM - 86, Barthel -62,3. FIM -apsitarnavimo srityje surenka -28 balus, sfinkterio kontrolès -4 , mobilumo - 12 , judejjimo - 7, bendravimo ir socialinès būklès -35 . Barthel indeksu vertinant sfinkterio kontrolę, asmuo surenka 10,2, o mobilumą - 13,7.

Analizuojant kitą asmenį, kuris jau 15 metų po C 6-7 pažeidimo, kojų paraparezè. Pagal pažeidimo lygi asmuo judina rankas, pilnai apsitarnauja valgydamas ir asmens tualeto veiksmuose, tačiau visiškai priklausomas tuštinimosi (FIM - 2, Barthel - 6), šlapinimosi (FIM - 2, Barthel - 7), rengimosi veiksmuose (FIM - 2, Barhel - 5) ir dalinai priklausomas maudymosi (FIM - 3, Barthel - 3) bei judejimo srityse (FIM (laiptai - 1, ejimas/vežimèlis - 5), Barthel (laiptai - 1,5, ejjimas/vežimèlis - 4,5 ).Bendras FIM - 90, o Barthel - 73,2.

LPC sporto stovyklos dalyvis, pažeidimo lygis - C6, sunki kojų parezè, septyni metai po traumos, FIM -109, Barthel - 69. Vertinant FIM socialinę ir bendravimo sritis vertinama 7 balais, sfinkterio kontrolè, mobilumas ir judèjimas 5 , o apsitarnavimas -7 balais (išskyrus viršutinès ir apatinès kūno dalies apsirengimą ir susitvarkymą tualete - 6). Tuo tarpu vertinant Barthl mobilumo ir judejimo sritis - surenkama 20 balų ir galimų 50 .

Neịgaliujų igalinimas yra ilgalaikis daugiapakopis so- 
3 lentelè. Fizinio aktyvumo lūkesčiai pagal funkcinį savarankiškumą ir pažeidimo lygi

\begin{tabular}{|c|c|c|c|}
\hline Pažeidimo lygis & \multicolumn{2}{|c|}{ Barthel } & Lūkesčiai \\
\hline \multicolumn{4}{|c|}{ LIETUVOS PARAPLEGIKŨ LANS̈AFTO TERAPIJOS CENTRAS } \\
\hline Th 8-9, koju paralyžius & \multicolumn{2}{|l|}{$\begin{array}{l}\text { Vidutiniškai } \\
\text { priklausomas }\end{array}$} & $\begin{array}{l}\text { "Daugiau jègos, sveikatai geriau“" } \\
\text {,Užimtumas, gal bus kokiu rezultatu“ }\end{array}$ \\
\hline Kojų parezė & \multicolumn{2}{|l|}{$\begin{array}{l}\text { Vidutiniškai } \\
\text { priklausomas }\end{array}$} & "Nebeturiu laiko sportui “" \\
\hline C5-6 hemiparezé & \multicolumn{2}{|c|}{ Šiek tiek priklausomas } & „, Numesti pilva, sustiprèti po žiemos“ \\
\hline C6 Sunki kojų parezè & \multicolumn{2}{|l|}{$\begin{array}{l}\text { Beveik visiškai } \\
\text { priklausomas }\end{array}$} & "Pagerinti bendra fizinę büklę" \\
\hline $\begin{array}{l}\mathrm{C} 4-\mathrm{Th} 5, \text { kojų ir liemens } \\
\text { paralyžius }\end{array}$ & \multicolumn{2}{|l|}{$\begin{array}{l}\text { Vidutiniškai } \\
\text { priklausomas }\end{array}$} & $\begin{array}{l}\text { "Numesti svorio, pagerinti savijauta" } \\
\text { „Tikimybè, ka nors pasiekti, sumažinti rutina" }\end{array}$ \\
\hline $\begin{array}{l}\text { Operuota } \\
\text { mielomeningocelè, kojų } \\
\text { paralyžius }\end{array}$ & \multicolumn{2}{|l|}{$\begin{array}{l}\text { Vidutiniškai } \\
\text { priklausomas }\end{array}$} & $\begin{array}{l}\text { "Sveikatai bus geriau" } \\
\text { "Vis kažkoks užsiemimas" }\end{array}$ \\
\hline $\begin{array}{l}\text { Diskozè, erkinis } \\
\text { encefalitas, raumenu } \\
\text { silpnumas }\end{array}$ & \multicolumn{2}{|l|}{$\begin{array}{l}\text { Vidutiniškai } \\
\text { priklausomas }\end{array}$} & $\begin{array}{l}\text { „, Geresnès sveikatos, emocinès būklès, retesniu } \\
\text { migrenos priepuoliu“" } \\
\text { „Ir nuotaika gerina, ir savijauta iškart geresnè “ }\end{array}$ \\
\hline $\begin{array}{l}\text { Th } 6 \text { kojų ir liemens } \\
\text { paralyžius }\end{array}$ & \multicolumn{2}{|l|}{$\begin{array}{l}\text { Vidutiniškai } \\
\text { priklausomas }\end{array}$} & $\begin{array}{l}\text { "Dèl savęs, toks jau gyvenimo büdas, judi ir } \\
\text { fizinis pajégumas dideja“" } \\
\text { „Laika praleisti su draugais“ }\end{array}$ \\
\hline Th 10-11 kojų paralyžius & \multicolumn{2}{|l|}{$\begin{array}{l}\text { Vidutiniškai } \\
\text { priklausomas }\end{array}$} & $\begin{array}{l}\text { "Tikiuosi geru ispüdžiu, fiziniu savybiu lavinimo } \\
\text { dabar ir ju palikymo ateityje " }\end{array}$ \\
\hline C 6-7 paraparezè & \multicolumn{2}{|l|}{$\begin{array}{l}\text { Vidutiniškai } \\
\text { priklausomas }\end{array}$} & $\begin{array}{l}\text { "Čia gal turi kažkiek sveikatai, kad neužsisèdèti, } \\
\text { bet šiaip man sunku būti labai aktyviam" }\end{array}$ \\
\hline Th 8-9, kojų paralyžius & \multicolumn{2}{|l|}{$\begin{array}{l}\text { Vidutiniškai } \\
\text { priklausomas }\end{array}$} & $\begin{array}{l}\text { "Na, aišku, raumenys tvirtesni, grynas oras } \\
\text { mano astmai geriau“ }\end{array}$ \\
\hline $\begin{array}{l}\text { C7 koju paralyžius, sunki } \\
\text { liemens kontrolè }\end{array}$ & \multicolumn{2}{|l|}{$\begin{array}{l}\text { Vidutiniškai } \\
\text { priklausomas }\end{array}$} & $\begin{array}{l}\text { "Gal kiek suplonèsiu čia büdamas, šiaip kažka } \\
\text { veiki, vis grynas oras ir pan. Vis pajudu daugiau } \\
\text { nei iprastai “ } \\
\text { "Daugiau malonumo, nei siekti kokiu rezultatu, } \\
\text { geriau užsiimti kuo nors tada kai noriu, } \\
\text { nemégstu tvarkaraščiu“ }\end{array}$ \\
\hline \multicolumn{4}{|c|}{ PALANGOS REABILITACIJOS LIGONINÉ } \\
\hline $\begin{array}{l}\text { Centriné } \\
\text { neurofibromatozè (NF2) }\end{array}$ & $\begin{array}{l}\text { Šiek tiek } \\
\text { priklausomas }\end{array}$ & \multicolumn{2}{|c|}{ „Noréčiau pradèti vaikščioti" } \\
\hline C4-5 kompresinis lūžis & $\begin{array}{l}\text { Vidutiniškai } \\
\text { priklausomas }\end{array}$ & $\begin{array}{l}\text {,Rec } \\
\text { namı } \\
\text {,Spo } \\
\text { susir }\end{array}$ & $\begin{array}{l}\text { litacijos užsièmimai pagerins mano fizinę būklę, } \\
\text { e minu dviratị ir bègtaki turiu“" } \\
\text { s teigiamai veikia, padeda realizuoti save, } \\
\text { i nauju bendraminčiu" }\end{array}$ \\
\hline GSI & $\begin{array}{l}\text { Šiek tiek } \\
\text { priklausomas }\end{array}$ & ,Nes & abai sportiška“ \\
\hline $\begin{array}{l}\text { C7 kompresija, } \\
\text { mielopatija }\end{array}$ & $\begin{array}{l}\text { Šiek tiek } \\
\text { priklausomas }\end{array}$ & ,, Sus & $\begin{array}{l}\text { réti" } \\
\text { a užsièmimas" }\end{array}$ \\
\hline C7- Th1 lūžis & $\begin{array}{l}\text { Vidutiniškai } \\
\text { priklausomas }\end{array}$ & ,Vis & vienoj vietoj “ \\
\hline $\mathrm{C} 4-5$ & $\begin{array}{l}\text { Vidutiniškai } \\
\text { priklausomas }\end{array}$ & $\begin{array}{l}, P a c \\
, \text {,Užs } \\
\text { traun }\end{array}$ & $\begin{array}{l}\text { sustiprèti ir nedegraduoti ratuose" } \\
\text { rbti ir nesédèti vietoje, aktyvus buvau prieš } \\
\text { toks ir noriu būti dabar" }\end{array}$ \\
\hline C6-7 kompresinis lūžis & $\begin{array}{l}\text { Vidutiniškai } \\
\text { priklausomas }\end{array}$ & $\begin{array}{l}\text { "Tik } \\
\text { žinal } \\
\text {,Ner }\end{array}$ & $\begin{array}{l}\text { greit atgausiu jègas, pradèsiu pilnai valdyti kojas, } \\
\text { tai užtruks" } \\
\text { bodžiai laikas eina" }\end{array}$ \\
\hline C7 lūžis & $\begin{array}{l}\text { Vidutiniškai } \\
\text { priklausomas }\end{array}$ & , Kin & $\begin{array}{l}\text { terapija ir kitos procedūros padeda sustiprèti, bet } \\
\text { usia išstrūkau iš namu " }\end{array}$ \\
\hline Stuburo osteochondrozè & $\begin{array}{l}\text { Vidutiniškai } \\
\text { priklausomas }\end{array}$ & $\begin{array}{l}\text {," Cia } \\
\text { pade } \\
\text {,Tik }\end{array}$ & $\begin{array}{l}\text { an gerai, laisvesnè, judresné jaučiuosi, mamkštos } \\
\text { geros mergaitès mankština" } \\
\text { kui praleisti arba su kitais tokiais kaip aš pabūti“" }\end{array}$ \\
\hline Stuburo kanalo stenozė & $\begin{array}{l}\text { Šiek tiek } \\
\text { priklausomas }\end{array}$ & , Vis & $\begin{array}{l}\text { a jaučiu pageréjima po procedūru, sveikata } \\
\text { Kažkodèl sportuoti nenoriu, pirmiausia reikia }\end{array}$ \\
\hline C5-6 lūžis & $\begin{array}{l}\text { Vidutiniškai } \\
\text { priklausomas }\end{array}$ & $\begin{array}{l}\text { "Pal } \\
\text { gyve } \\
\text {,Net } \\
\text { neblc }\end{array}$ & $\begin{array}{l}\text { "yti gera fizinę forma, kad bütu kuo lengviau } \\
\text { u kur energijos dèti, tai nuleisti "gara" visai } \\
\text { i"“ }\end{array}$ \\
\hline L1-2 disko išvarža & $\begin{array}{l}\text { Vidutiniškai } \\
\text { priklausomas }\end{array}$ & $\begin{array}{l}\text {,Ma } \\
\text { nelei } \\
\text { išjud } \\
\text {,Da } \\
\text { nebe }\end{array}$ & $\begin{array}{l}\text { ia gerai, šiek tiek svorio numečiau, mankštos } \\
\text { a susidaryti sąstingiui. Kaip reikalas čia visus } \\
\text { "“ } \\
\text { "jau neisivivaizduoju savęs sportuojančio, tik } \\
\text { pasivažinejimas gryname ore su šeima" }\end{array}$ \\
\hline $\mathrm{C} 4-5$ & $\begin{array}{l}\text { Vidutiniškai } \\
\text { priklausomas }\end{array}$ & $\begin{array}{l}\text {,Kin } \\
\text { susti } \\
\text { nuot }\end{array}$ & $\begin{array}{l}\text { terapija man padeda, rankos ne tokios } \\
\text { usios, pirštus va pradèjau daugiau lankstyti. Ir } \\
\text { a geresnè, kai visi tokie kaip aš “ }\end{array}$ \\
\hline Th12-L1 & $\begin{array}{l}\text { Vidutiniškai } \\
\text { priklausomas }\end{array}$ & "Pac & atsistatyti, o véliau ir vaikščioti " \\
\hline Th10-11 & $\begin{array}{l}\text { Vidutiniškai } \\
\text { priklausomas }\end{array}$ & ,Tik & si po reabilitacijos pradèsiu vaikščioti ir be \\
\hline C6-7 & $\begin{array}{l}\text { Vidutiniškai } \\
\text { priklausomas }\end{array}$ & $\begin{array}{l}\text {, Ger } \\
\text { pake } \\
, \text {,Kac }\end{array}$ & $\begin{array}{l}\text { praleisti laika, gal kojos pastiprès, šiaip aplinkq } \\
\text { nksma būtu “ }\end{array}$ \\
\hline GSI & $\begin{array}{l}\text { Vidutiniškai } \\
\text { priklausomas }\end{array}$ & $\begin{array}{l}\text { Dai } \\
\text { Diev } \\
\text { gimn }\end{array}$ & $\begin{array}{l}\text { isakè, bus geriau po sanatorijos, o kaip čia bus, } \\
\text { zino. Lanksto man tas kojas, liepia visokiq } \\
\text { tika daryti, gal ir geriau bus, gal stipresnis büsiu“ }\end{array}$ \\
\hline
\end{tabular}

cialinis procesas, apimantis tarpusavio santykių kūrimą, bendrumo jausmo puoselèjimą, skatinimą bendrai tarpusavio veiklai, savarankiškumo vertinimas negali apsiriboti tik testavimu, todèl mes vertinome ir jų fizinę negalią, savarankiškumą bei fizinès veiklos lūkesčius (3 lentelè).

Ivertinę Lietuvos paraplegikų terapijos centro klientu požiūrị į fizinę veiklą nustatème, kad dauguma respondentų buvo ,vidutiniškai priklausomi „nuo aplinkiniu pagalbos (Barthel indeksas) ir tik vienas buvo „beveik visiškai priklausomas“. Visų respondentų požiūris i fizinę veiklą buvo pozityvus:

- , Tikiuosi geru ìspūdžiu, fiziniu savybiu lavinimo dabar ir ju palaikymo ateityje;

„Geresnès sveikatos, emocinès büklès, retesniu migrenos priepuoliu“";

",Tikimybè ka nors pasiekti, sumažinti rutina “.

Vertindami Palangos reabilitacijos ligonineje besigydančių respondentų savarankiškumą, nustatėme, kad dauguma respondentų buvo „vidutiniškai priklausomi,, nuo medicinos ir paramedikų personalo ir keturi, pagal Barthel indeksą, buvo šiek tiek priklausomi“.

Pacientų lūkesčiai dèl fizinès veiklos buvo pozityvūs keturiais aspketais:

- Fizinių galimybiu atgavimas - „Padès atsistatyti, o véliau ir vaikščioti “; , Kineziterapija man - padeda, rankos ne tokios sustingusios, pirštus va pradejjau daugiau lankstyti. Ir nuotaika geresné, kai visi tokie kaip aš “; „Noréčiau pradèti vaikščioti“.

- Nauja patirtis - ,Sportas teigiamai veikia, padeda realizuoti save, susirasti nauju bendraminčiu"; „,Vis ne vienoj vietoj"; „Užsidirbti ir nesédèti vietoje, aktyvus buvau prieš trauma, toks ir noriu büti dabar".

- Teigiamos emocijos - „Čia man gerai, laisvesné, judresne jaučiuosi, mankštos padeda, geros mergaitès mankština"; ,,Tik laikui praleisti arba su kitais tokiais kaip aš pabūti“; , ,Vaikai sake, bus geriau po sanatorijos, o kaip čia bus, Dievas žino. Lanksto man tas kojas, liepia visokia gimnastika daryti, gal ir geriau bus, gal stipresnis büsiu“.

- Kūno įvaizdis - ,,Man čia gerai, šiek tiek svorio numečiau, mankštos neleidžia susidaryti sąstingiui. Kaip reikalas čia visus išjudina “; ,, Tikiuosi po reabilitacijos pradesiu vaikščioti ir be lazdu“;,,Palaikyti gera fizine forma, kad būtu kuo lengviau gyventi."

\section{Išvados}

1. Respondentai nepriklausomai nuo savarankiš- 
kumo lygio sugeba individualiame ir bendrame socialinès aplinkos lygmenyje spręsti kasdieninès veiklos problemas, kontroliuoti nuotaikas ir įvertinti apsisprendimo galimybes (FIM- 35b).

2. Atliekant kasdieninių veiklų vertinimo tyrimą Barthel ir FIM indeksais, nustatėme, kad savarankiškumui turejo įtakos pažeidimo lygis ir laiko tarpas po ligos ar traumos.

3. Lygindami respondentų fizinès veiklos lūkesčius nustatème skirtumus tarp PRL pacientų ir LPC klientų. Pacientai fizinès veiklos poveiki vertino keturiais aspektais, iš kurių labiausiai vertino fizinès veiklos poveiki jų fizinèms galimybèms atstatyti. Tuo tarpu LPC klientai fizinę veiklą vertino kaip galimybę pagerinti bendrą sveikatos būklę ir patirti teigiamas emocijas.

\section{Literatūra}

1. Crocker $\mathrm{J}$ and Wolfe C. Contingencencies of self - worth. Psychological Review 2001.

2. Tangney J, Baumeister RF, Boone A, L. High self-control predicts good adjustment, less pathology, better, grades, and interpersonal success. Journal of Personality 2004; 72: 271-324.

3. Sherrill C. Adapted physical activity, recreation and sport: Cross disciplinary and life - span $\left(5^{\text {th }}\right.$ ed). Dubuque, IA: Brown and Benchmark 1998.

4. Samsonienė L, Baubinas B, Adomaitienė R, Jankauskienė K, Korotkich I, Kèvelaitis E. Neigaliujų sportininkų gyvenimo kokybė ir kai kurie lygių galimybių aspektai. Medicina, (Kaunas) 2010 ; 46(3):211-8

5. Samsonienė L., Adomaitienè R., Krivičiūtė J., Jankauskienè K., Jurkšienè V., Kèvelaitis E. Neigaliuju socializacija taikomojoje fizinèje veikloje. Medicina, ISSN 1010-660x. 2008; 44(11): 877-884.

6. Juozulynas A., Jurgelènas A., Samsonienė L., Stukas R., Butkienė B., Gocenas A. Negalios ịtaka sportuojančių asmenų gyvenimo kokybès fizinei sričiai. Medicinos teorija ir praktika, 2011; 1(17):15-22.

7. Hur H. M. Empowerment in terms of theoretical perspectives: exploring a typology of the process and components across disciplines. Journal of Community Psychology 2006; 34(5): 523-540.
8. Becker J, Kovach AC \& Gronseth DL. Individual empowerment: How community health workers operationalize self-determination, self-sufficiency, and decision-making abilities of low-income mothers. Journal of Community Psychology 2004; 32(3): 327-342.

9. Larson R, Walker K \& Pearce NA. Comparison of youth-driven and adult-driven youth programs: Balancing inputs from youth and adults. Journal of Community Psychology 2005: 33(1): $57-74$.

10. Ryan R \& Deci E. Self-Determination theory and facilitation of intrinsic motivation, social development and well-being. American Psychologist 2000; 55(1): 68-78.

\section{DISABLED, WHEELCHAIR USERS THE OPPORTUNITLY TO EXPRES PHYSICAL ACTIVITY OF PERSPECTIVE V. Stankutè, L. Samsonienè, A. Juozulynas}

Key words: disability, autonomy, physical activity and disability. Summary

Recognizing the power of people with disabilities in physical activities, regardless of their abilities, we establish the conditions for their effective development: encourage their self-expression, self-image, self-esteem and improve body image. Objective of the study - to assess the self-sufficiency and personal physical activity experience and a real need. Take the test - 29 respondents with a physical disability and moving wheelchair. The study was conducted in 2014. In July and August, Palanga drug prevention in the hospital and the Lithuanian Association of paraplegics lanšafto therapy and reakreacijos center. Research methods - in order to find out personal empowerment of the individual factors and the overall social environment level, through personal expression conditions, dynamic and self determination was applied qualitative research method, using a semi-structured interview data collection method and the open and closed reference questions; the level of independence of the respondents assessed the FIM and Barthel index. The results - regardless of the severity of disability, level of independence, and time after injury or illness, physical activity, respondents evaluated positively: positive emotions, new experiences, good health, positive body image.

Correspondence to: a.juozulynas@imcentras.lt

Gauta 2014-11-10 